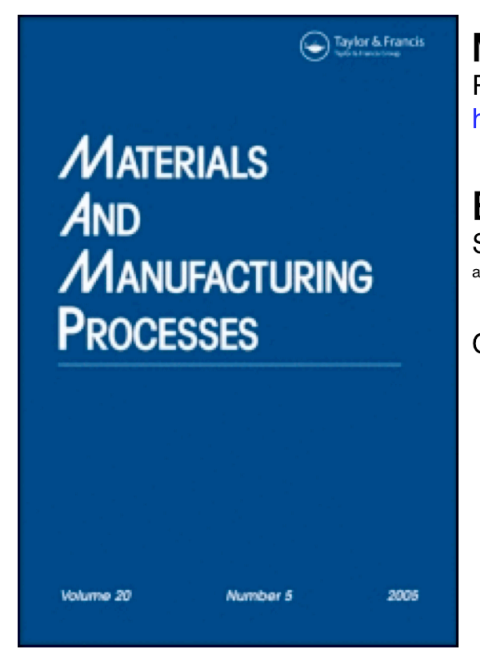

Materials and Manufacturing Processes

Publication details, including instructions for authors and subscription information:

http://www.informaworld.com/smpp/title content=t713597284

\title{
Elongation of Irradiated Steels
}

S. Forsik ${ }^{\text {a; H. K. K. H. Bhadeshia }}{ }^{\text {a }}$

a Department of Materials Science and Metallurgy, University of Cambridge, Cambridge, UK

Online Publication Date: 01 February 2009

To cite this Article Forsik, S. and Bhadeshia, H. K. D. H.(2009)'Elongation of Irradiated Steels',Materials and Manufacturing Processes,24:2,130 - 137

To link to this Article: DOI: $10.1080 / 10426910802609144$

URL: http://dx.doi.org/10.1080/10426910802609144 


\title{
Elongation of Irradiated Steels
}

\author{
S. Forsik and H. K. D. H. Bhadeshia \\ Materials Science and Metallurgy, University of Cambridge \\ Cambridge CB2 3QZ, U.K., www.msm.cam.ac.uk/phase-trans
}

\begin{abstract}
A neural network was designed to model the elongation of neutron-irradiated steels. Predictions were compared to experimental values and were in agreement. The model was extrapolated to predict the elongation at high irradiation doses $(200 \mathrm{dpa})$ and high temperatures $\left(750^{\circ} \mathrm{C}\right)$. Because of the lack of experimental values at such doses and temperatures, predictions were accompanied with very large modelling uncertainties.
\end{abstract}

Keywords: low-activation steel, irradiation, elongation, ductility, empirical modelling.

\section{Reduced-Activation Steels}

The formation of voids during irradiation with neutrons causes the swelling of metals. Irradiation damage involves the creation of both interstitials and vacancies in equal concentrations, but the former anneal out more rapidly than the latter. The resulting excess concentration of vacancies is relieved by condensation into voids. Ferrite has a much higher resistance to void swelling than austenite, although nickel base alloys rank alongside the ferritic steels [1]. Point defects introduced by irradiation condense at neutral or biassed sinks. The latter are typically dislocations with large Burgers vectors, attracting more interstitials than vacancies. It follows that a large density of neutral sinks enhances the swelling resistance.

It is believed that in ferritic steels, irradiation induces the formation of two kinds of dislocations, one of which is strongly biassed whereas the other is neutral. This provides sinks for both interstitials and vacancies, resulting in a smaller excess of void-forming vacancies. It is for their swelling resistance that ferritic steels have been considered for structural applications in the construction of the first wall and blanket structures of fusion reactors. But the alloys must be such that radioactivity decays rapidly once the steels are removed from nuclear exposure. These are the so-called reduced activation alloys which have minimal concentrations of $\mathrm{Mo}, \mathrm{Ni}, \mathrm{Nb}, \mathrm{Cu}$ and nitrogen, all of which have long-lived radioactive isotopes [2,3]. For example, molybdenum and niobium in steel can be induced by neutron bombardment to transmute into radioactive species such that the decay time to reach a safe level of radioactivity ( 25 micro Sieverts per hour) is of the order of $10^{5} \mathrm{~h}$. Some of these 
undesirable elements are key constituents of creep-resistant steels, but they can be eliminated by using tungsten instead of molybdenum and by substituting vanadium and tantalum for niobium.

To summarise, ferritic steels are likely candidates in the design of fusion reactors and if implemented will be exposed to $14 \mathrm{MeV}$ neutrons and total irradiation doses of some $\approx 200$ dpa [4]. A great deal of research is underway to study the consequences of such an environment on the properties of the steels, but because appropriate experimental facilities do not exist, much of the work is theoretical. Back-propagation artificial neural networks were recently been used to model the yield strength and the ductile-to-brittle transition temperature of irradiated steels $[5,6]$. Here we extend the work to estimating the elongation of irradiated steels.

\section{Elongation of Irradiated Steels}

Irradiated samples accumulate defects and transmutation products (primarily $\mathrm{He}$ ) which by obstructing the motion of dislocations increase the yield strength and reduce elongation. The irradiation dose and temperature directly influence the elongation, which usually decreases within the first moments of the irradiation as the concentration of defects increases. Above a certain dose, the defects reorganise in dislocations, loops and dislocation networks. A saturation in hardening and reduction of the elongation appear during the transition from loop nucleation to loop growth; the elongation then reaches a minimum and remains at this value or increases again, depending on the irradiation conditions.

Tensile elongation is controlled by many factors, including details of the structure (atomic and microstructure, inclusions), plasticity (work-hardening coefficient as a function of strain, homogeneity of deformation, strain rate, temperature) and size effects. It is not possible to calculate elongation from first principles and yet such information is essential. An attempt is therefore made here to develop an experience-based quantitative model using the neural network method. The database needed to do this is discussed next.

\section{Database}

Elongation values from 408 irradiation experiments and 1155 tensile tests on unirradiated samples were compiled into an extensive set including the classical candidate steels Eurofer'97, F82H and steels such as $2.25 \mathrm{Cr}$. Parameters most likely to influence the elongation were used as inputs: heat treatment, chemical composition, helium concentration, radiation dose, irradiation and tensile-test temperatures (Table 1). Elongation values for unirradiated steels were provided by the National Institute of Materials Science (Japan) [7]. For unirradiated specimens, the irradiation dose and helium concentration were set to zero and the irradiation temperature to $298 \mathrm{~K}$.

Artificial parameters were used as additional inputs to help the model find complex relations between inputs and the output. This includes the Arrhenius expression $\exp \left(\frac{-Q}{R T}\right)$ to capture thermal activation effects in heat treatment, $\sqrt{\mathrm{dpa}}$ because it is related to the nucleation rate of helium bubbles [8] and $\ln$ (time) since kinetic phenomena often vary logarithmically with time. 


\begin{tabular}{lcccc}
\hline Parameter & Minimum & Maximum & Average & Standard deviation \\
\hline$T_{\gamma} / \mathrm{K}$ & 1143 & 1323 & 1237 & 60 \\
$t_{\gamma} / \mathrm{min}$ & 10 & 540 & 67 & 99 \\
$T_{T} / \mathrm{K}$ & 898.15 & 1053 & 991 & 44 \\
$t_{T} / \mathrm{min}$ & 30 & 660 & 125 & 130 \\
$\mathrm{C} / \mathrm{wt} \%$ & 0.064 & 0.34 & 0.130 & 0.043 \\
$\mathrm{Cr} / \mathrm{wt} \%$ & 0.0001 & 13.6 & 5.5 & 4.2 \\
$\mathrm{~W} / \mathrm{wt} \%$ & 0 & 2.17 & 0.44 & 0.74 \\
$\mathrm{Mo} / \mathrm{wt} \%$ & 0 & 1.59 & 0.47 & 0.38 \\
Ta / wt\% & 0 & 0.14 & 0.02 & 0.04 \\
$\mathrm{~V} / \mathrm{wt} \%$ & 0 & 0.31 & 0.09 & 0.12 \\
$\mathrm{Si} / \mathrm{wt} \%$ & 0 & 0.86 & 0.27 & 0.19 \\
$\mathrm{Mn} / \mathrm{wt} \%$ & 0 & 2.09 & 0.53 & 0.21 \\
$\mathrm{~N} / \mathrm{wt} \%$ & 0 & 0.17 & 0.013 & 0.016 \\
$\mathrm{Cu} / \mathrm{wt} \%$ & 0 & 0.25 & 0.051 & 0.05 \\
Nb / wt\% & 0 & 0.075 & 0.006 & 0.017 \\
Ni / wt\% & 0 & 2.3 & 0.18 & 0.42 \\
$\mathrm{P} /$ wt\% & 0 & 0.03 & 0.011 & 0.007 \\
Ti / wt\% & 0 & 0.052 & 0.002 & 0.005 \\
Irradiation temperature / K & 293 & 1146 & 366 & 156 \\
Irradiation dose / dpa & 0 & 72 & 3.2 & 9.4 \\
Helium / appm & 0 & 5000 & 61 & 388 \\
Test temperature / K & 109 & 973 & 587 & 212 \\
Elongation / \% & 0.04 & 105 & 22 & 15 \\
\hline
\end{tabular}

Table 1: Properties of database used to create the mathematical models. $T_{\gamma}$ and $t_{\gamma}$ are the austenitisation temperature and time respectively, and $T_{T}$ and $t_{T}$ the tempering temperature and time respectively.

\section{Model}

It is not the intention here to describe the neural network method; details can be found in [9-12] and the particular method used here has been widely applied in the discovery of phenomena in steels [13-22]. However, a brief explanation of particular aspects is justified in order to set the scene for later discussions.

A Bayesian environment allows the estimation of modelling uncertainties, i.e., to what extent can the same data be represented by a variety of different mathematical formulations without unduly compromising the fit in the region where experiments exist. The individual formulations may then extrapolate differently, giving an indication both of the dangers of extrapolation and also identifying domains where further experiments are needed.

The conventional error which all empirical regression methods consider is the noise, which represents the effect of uncontrolled variables. This parameter is also estimated for each of our models [9-12]. 
Overfitting is controlled partly by studying the generalisation of each model on unseen test-data, and partly via the Bayesian framework [9-12]. Whereas the noise can decrease with increase complexity (Fig 1a) the error in predicting the test data is expected to go through a minimum when an optimum level of complexity is discovered which does not model noise, nor is it too simple to capture real trends (Figure 1b).

Finally, we have also used an optimum committee of models in order to obtain the best ability to extrapolate [9-12]. The resulting performance is illustrated in Fig. 2 where the uncertainties represent $\pm 1 \sigma$ where $\sigma$ is the combined effect of noise and modelling uncertainty. The correlation is good but there are a number of outliers, i.e., points which are are many $\sigma$ away from the line of perfect fit, making them rather improbable.
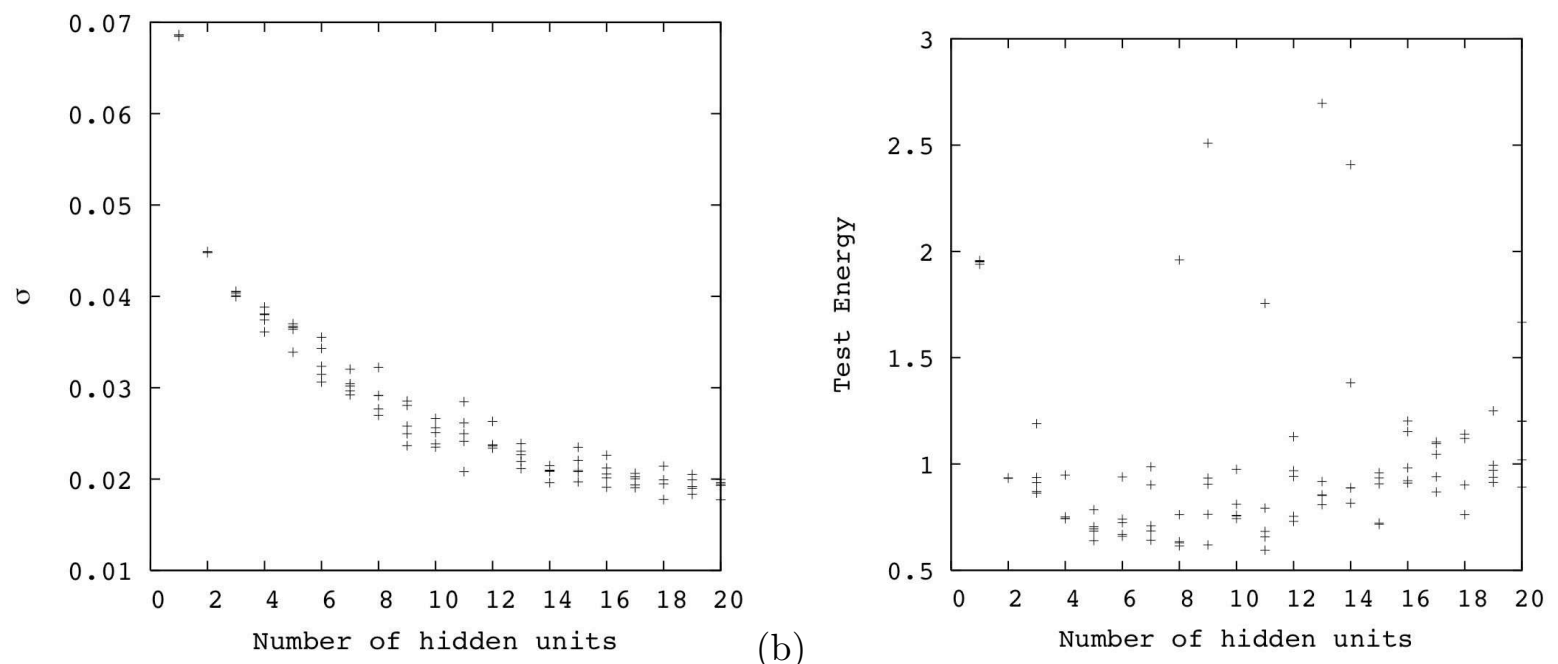

Figure 1: (a) Noise and the (b) error in predicting the test data, as a function of the complexity of the model.

For every input, it was possible to calculate a significance, which is a measure of the ability of an input to explain variations in the output, rather like a partial correlation coefficient. Figure 3 naturally shows that the temperature at which the tensile test is conducted is significant, but it is noteworthy that chromium is highlighted and its influence is explored in detail later in the text.

\section{Predictions}

The ability of the network to model the elongation of irradiated steels was tested by making predictions for three parameters which are believed to be vital: the test temperature, the irradiation dose and the chromium concentration. 


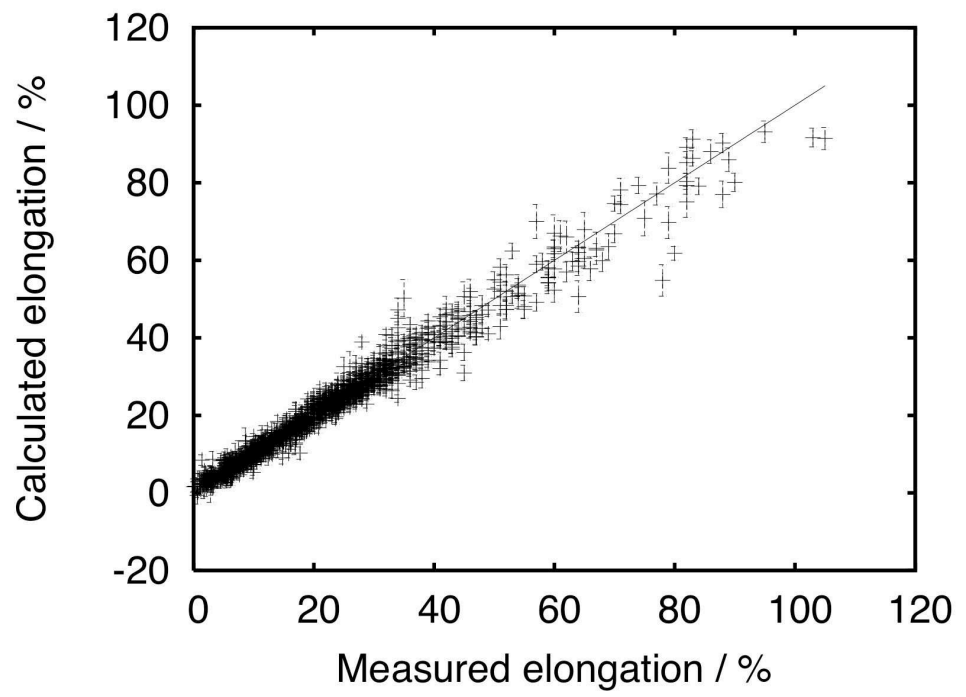

Figure 2: The confidence with which the optimum committee of models estimates the known data.

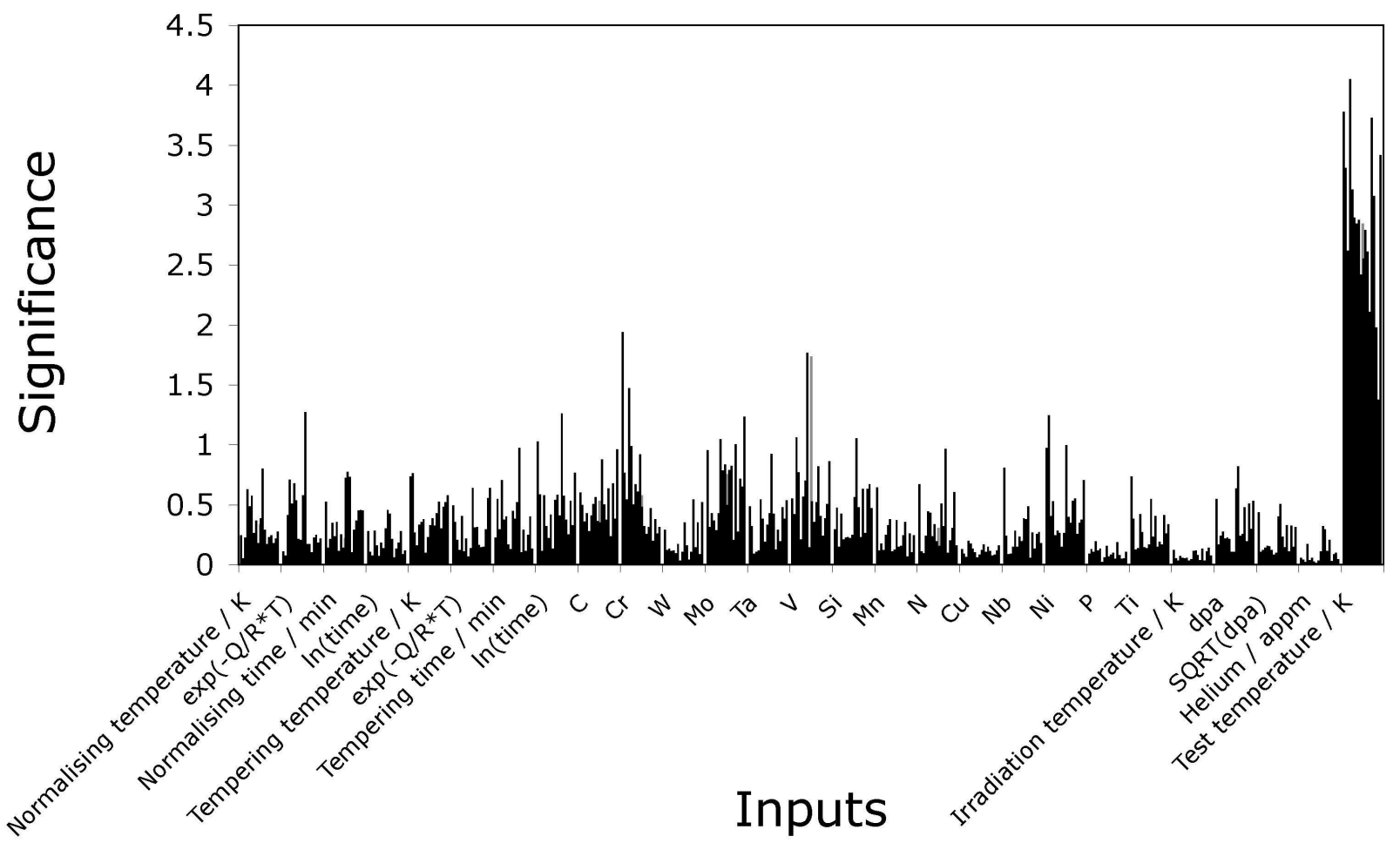

Figure 3: Significance of individual inputs. Since the committee of models contains eighteen members, there is a corresponding number of bars associated with each input. 


\section{$5.1 \quad$ Test temperature}

Chromium is of particular relevance because, for reasons which are not entirely clear, the extent of embrittlement of ferritic steels due to irradiation seems to go through a minimum at about $9 \mathrm{wt} \% \mathrm{Cr}$ in one of the candidate steels (Eurofer) for the future fusion power plant project [23]. One possibility is that at large chromium concentrations irradiation leads to the precipitation of $\alpha$-chromium but, as pointed out by Cottrell et al., the situation for concentrations less than $9 \mathrm{wt} \%$ is not explained.

The elongation of three classical, creep-resistant chromium-containing alloys [24] with nominal concentrations: $2.25 \mathrm{wt} \% \mathrm{Cr}, 9 \mathrm{wt} \% \mathrm{Cr}$ and $12 \mathrm{wt} \% \mathrm{Cr}$ was calculated in the absence of irradiation. Note that these are not reduced-activation steels but are nevertheless interesting to study because they are well-established. Their compositions and heat treatments are listed in Table 2.

Table 2: Chemical compositions in wt\%. The W, Ta, V, Nb and Ti concentrations are zero.

\begin{tabular}{lccccccccc}
\hline Alloy & $\mathrm{C}$ & $\mathrm{Cr}$ & $\mathrm{Mo}$ & $\mathrm{Si}$ & $\mathrm{Mn}$ & $\mathrm{N}$ & $\mathrm{Cu}$ & $\mathrm{Ni}$ & $\mathrm{P}$ \\
$2.25 \mathrm{Cr}$ & 0.12 & 2.2 & 0.99 & 0.29 & 0.48 & 0.0095 & 0.07 & 0.05 & 0.015 \\
$9 \mathrm{Cr}$ & 0.11 & 9.15 & 1.05 & 0.59 & 0.41 & 0.018 & 0.02 & 0.1 & 0.017 \\
$12 \mathrm{Cr}$ & 0.12 & 12.38 & 0.09 & 0.48 & 0.71 & 0.0194 & 0.09 & 0.31 & 0.026 \\
\hline Alloy & $T_{\gamma} / \mathrm{K}$ & $t_{\gamma} / \mathrm{min}$ & & $T_{T} / \mathrm{K}$ & & \multicolumn{2}{c}{$t_{T} / \mathrm{min}$} \\
$2.25 \mathrm{Cr}$ & 1203 & 60 & & 993.15 & & \multicolumn{2}{c}{180} \\
$9 \mathrm{Cr}$ & 1243 & 20 & & 1013.15 & & \multicolumn{2}{c}{90} \\
$12 \mathrm{Cr}$ & 1243 & 30 & & 1023.15 & & \multicolumn{2}{c}{60} \\
\hline
\end{tabular}

The calculated values and associated uncertainties are plotted alongside the measured values in Figure 4a; the large increase in elongation at high temperatures is expected because the steels should all soften in those circumstances. It is clear that the model has essentially captured the expected behaviour for temperatures below $700 \mathrm{~K}$ but there are discrepancies for higher temperatures. It is interesting however, that the elongation data themselves show that the $9 \mathrm{Cr}$ steel systematically has the highest elongation. To check whether this is due to the chromium concentration or other variables, the calculations were repeated by setting all the parameters other than $\mathrm{Cr}$ to be equal to those of the $9 \mathrm{Cr}$ alloy - the results then show an insignificant difference between the 9 and $12 \mathrm{Cr}$ steels, Figure $4 \mathrm{~b}$. It is evident that the difference between the $12 \mathrm{Cr}$ and $9 \mathrm{Cr}$ alloys in Figure $4 \mathrm{a}$ cannot reasonably be attributed to their chromium concentrations alone.

The effect of irradiation at 20 and $100 \mathrm{dpa}$ on the same alloys is illustrated in Fig. 5. Although there is some deterioration in elongation at $20 \mathrm{dpa}$, that at $100 \mathrm{dpa}$ seems to increase, although it could be argued that the modelling uncertainties are too large to reach a confident conclusion. It speculated that a large number of displacements per atom can cause the dissolution of precipitates introduced during the tempering heat-treatments, which could in principle lead to a greater elongation. 


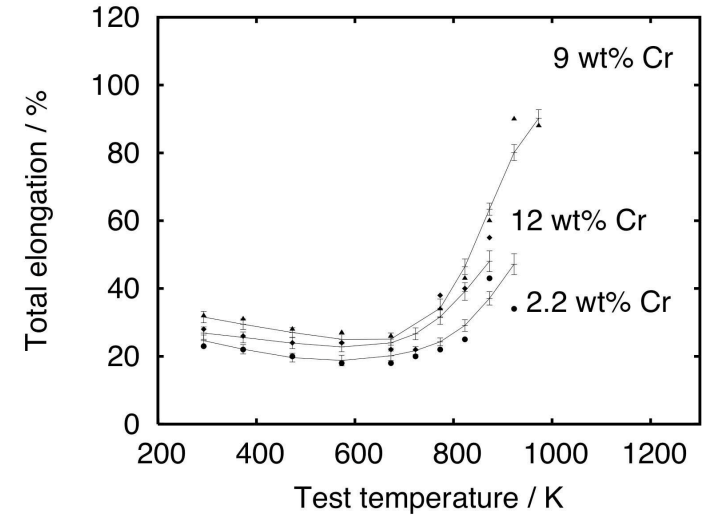

(a)

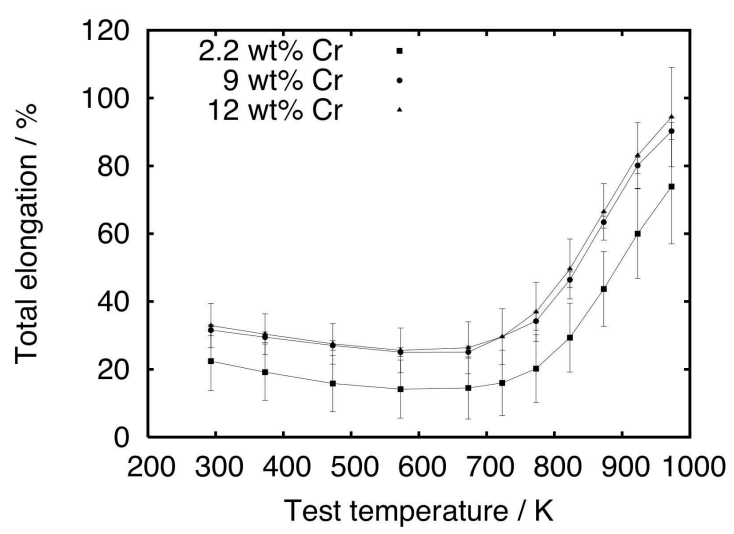

(b)

Figure 4: Unirradiated steels: (a) Experimental and calculated values of elongation for steels whose parameters are listed in Table 2. (b) As (a) but with the exception of Cr, all other input parameters have been set equal to that of the $9 \mathrm{Cr}$ alloy.

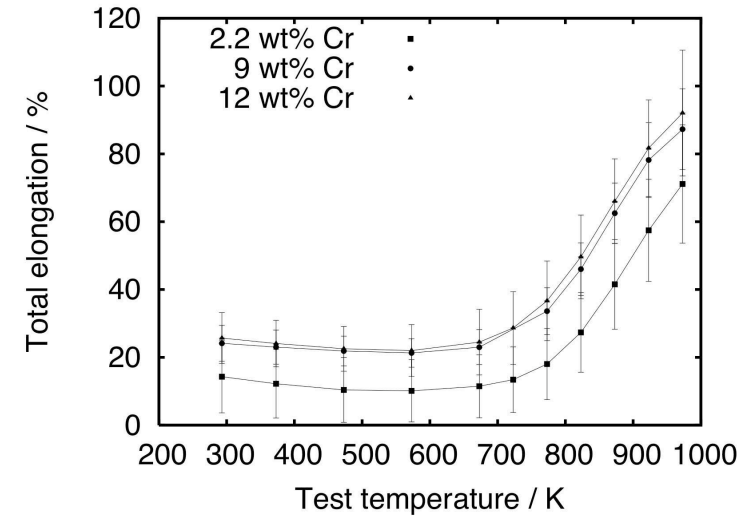

(a)

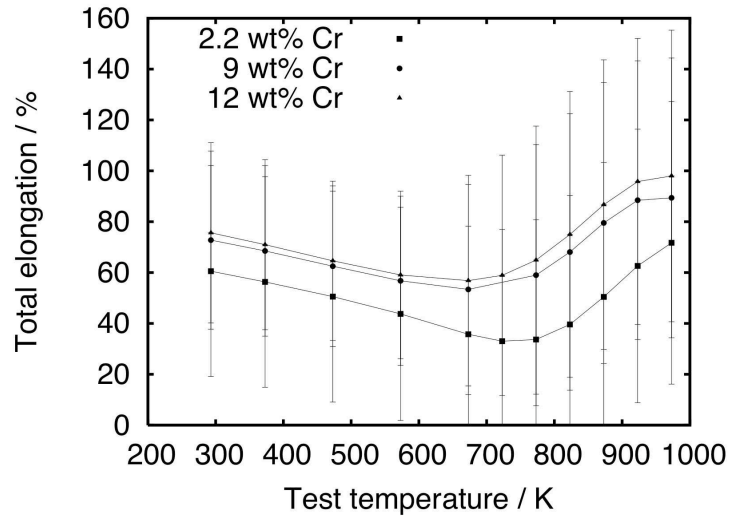

(b)

Figure 5: Input parameters as for Fig. 4 but with irradiation at (a) 20 dpa and (b) 100 dpa. Steels were irradiated and tested at the same temperature. 


\subsection{Irradiation Dose}

The calculated elongations and associated uncertainties, as a function of the displacements per atom (dpa), together with experimental data $[25,26]$ represented as points, are given in Figure 6a for three different alloys labelled $2.25 \mathrm{Cr}, 9 \mathrm{Cr}-2 \mathrm{WVTa}$ and $12 \mathrm{Cr}-1 \mathrm{MoVW}$. The chemical compositions and heat treatments are given in Table 3.

Table 3: Chemical composition in wt\%. The nitrogen concentration is zero.

\begin{tabular}{lccccccccccc}
\hline Alloy & $\mathrm{C}$ & $\mathrm{Cr}$ & $\mathrm{W}$ & $\mathrm{Mo}$ & $\mathrm{Ta}$ & $\mathrm{V}$ & $\mathrm{Si}$ & $\mathrm{Mn}$ & $\mathrm{Cu}$ & $\mathrm{Nb}$ & $\mathrm{Ni}$ \\
$2.25 \mathrm{Cr}$ & 0.11 & 2.36 & 0 & 0.01 & 0.005 & 0.25 & 0.17 & 0.4 & 0.02 & 0.005 & 0.01 \\
9Cr-2WVTa & 0.1 & 8.72 & 2.09 & 0 & 0.075 & 0.23 & 0.23 & 0.43 & 0 & 0 & 0 \\
12Cr-1MoVW & 0.2 & 11.71 & 0.54 & 1.02 & 0 & 0.31 & 0.13 & 0.49 & 0.05 & 0.015 & 2.27 \\
\hline Alloy & $\mathrm{P}$ & $\mathrm{Ti}$ & $T_{\gamma} / \mathrm{K}$ & $t_{\gamma} / \mathrm{min}$ & & $T_{T} / \mathrm{K}$ & & $t_{T} / \mathrm{min}$ \\
$2.25 \mathrm{Cr}$ & 0.015 & 0.005 & 1323 & 60 & & 973 & & 60 \\
9Cr-2WVTa & 0.015 & 0 & 1323 & 60 & & 1023.15 & 60 \\
12Cr-1MoVW & 0.011 & 0.003 & 1323 & 30 & & 973 & & 300 \\
\hline
\end{tabular}

(a)

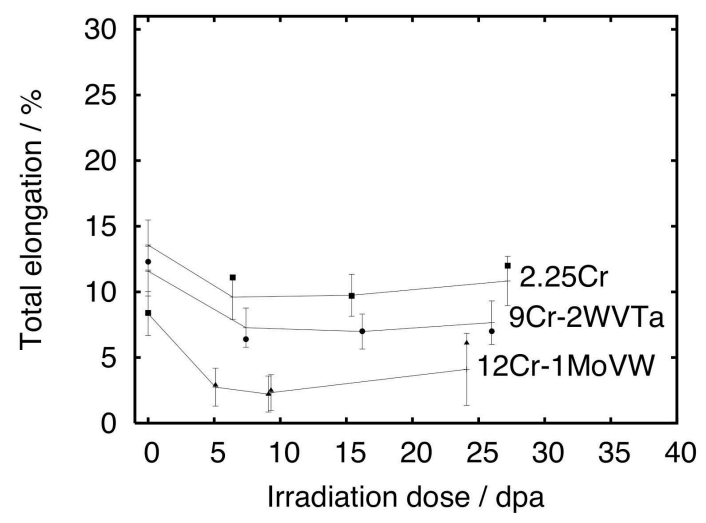

(b)

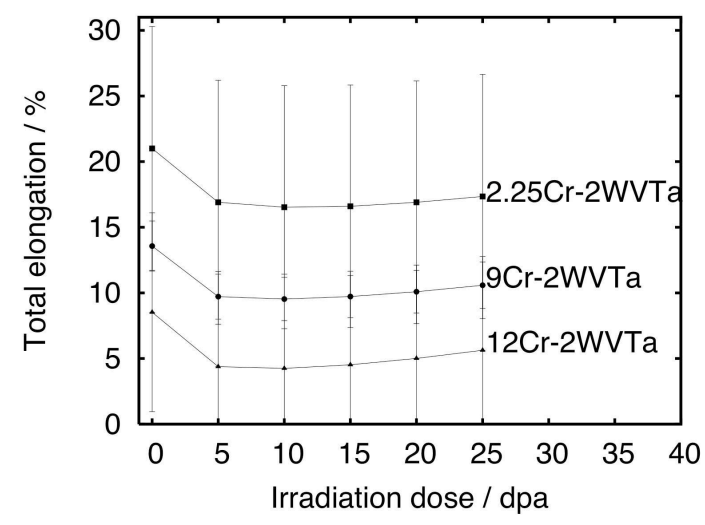

Figure 6: Elongation calculations for (a) the alloys listed in Table 3. (b) Cr concentrations as for (a) but all other parameters set to be those of the 9C-2WVTa alloy.

A minimum in the elongation is observed at 5-10 dpa for all the three alloys (only $2 \%$ at 10 dpa for the $12 \mathrm{wt} \% \mathrm{Cr}$ alloy), followed by a recovery as the dose increases. This low elongation has previously been noted [26] and is attributed to the onset of channel deformation [27] in which dislocations sweep out defect-free channels so that subsequent deformation in these channels becomes easier, leading to heterogeneous deformation. The minimum in total elongation is explained by the growth of dislocation loops as the irradiation dose increases, making it more difficult to form channels and hence rendering deformation more homogeneous.

Figure $6 \mathrm{~b}$ shows the same calculations as Figure 6a, but with all the parameters set to be those of the $9 \mathrm{C}-2 \mathrm{WVTa}$ alloy with the exception of the chromium concentration which is set to the values stated in Table 3. These calculations were done to see whether the observed effects of chromium are intrinsic to that element or whether other factors play a role. It is evident that the difference 
between the 12 and $9 \mathrm{Cr}$ steels vanishes and the calculation shows that the $2.25 \mathrm{Cr}$ alloy has a higher elongation than the $9 \mathrm{Cr}$ and $12 \mathrm{Cr}$. This is consistent with previous work on low-chromium alloys (Klueh et al. [28]) where several chromium-tungsten steels with Cr concentrations of 2.25, 5, 9 and $12 \mathrm{wt} \%$ were tested. It was proved that the $2.25 \mathrm{Cr}-2 \mathrm{WV}$ alloy had the highest strength.

\subsection{Chromium Concentration}

As mentioned previously, the literature suggests that $7-9 \mathrm{wt} \% \mathrm{Cr}$ alloys show a lesser tendency to irradiation hardening and have a better resistance to radiation damage [5, 29]. However, in the present work we do not find a clear optimum in chromium concentration with respect to ductility, particularly when the calculations are done with all the other variables kept constant.

The variation in elongation $\left(\Delta \mathrm{E}=\mathrm{E}_{\text {unirradiated }}-\mathrm{E}_{\text {irradiated }}\right)$ of a $9 \mathrm{Cr}-2 \mathrm{WVTa}$ [25] alloy was modelled at three different irradiation temperatures (293, 493 and $693 \mathrm{~K})$. Figure 7 shows estimates for the Cr-2WVTa system based around the Eurofer97 design, both for the unirradiated and irradiated states. There is no evidence to suggest that there is an advantage in keeping the chromium concentration in the range $7-9 \%$.

One aspect worth pointing out is that some of the reported observations are based on differences rather than absolute values. For example, $\triangle \mathrm{DBTT}$ (the change in the ductile-brittle transition temperature relative to the unirradiated state). This may be misleading because a brittle material would be expected to have a smaller $\triangle \mathrm{DBTT}$ even though an irradiated ductile material may have a better toughness.

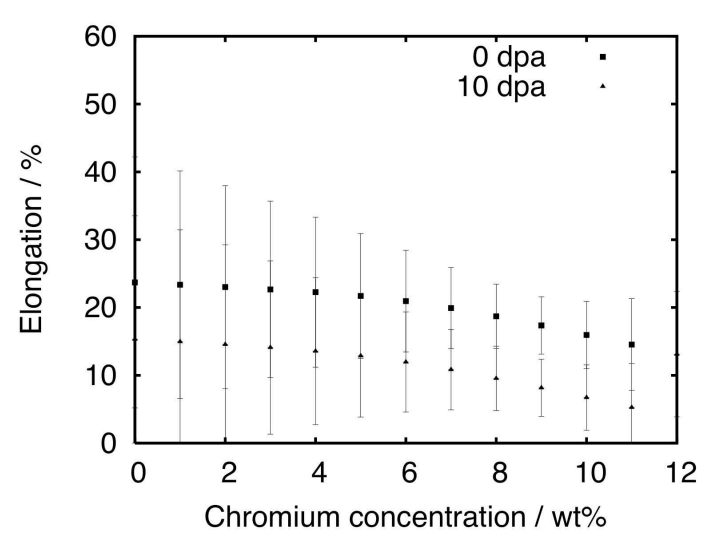

(a)

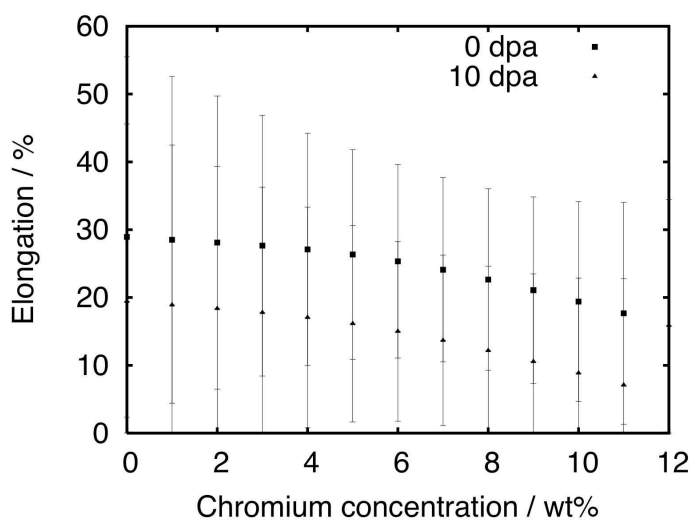

Figure 7: Elongation calculations for 9Cr2WVTa (a) and Eurofer97 (b) at two irradiation doses, 0 and $10 \mathrm{dpa}$, as a function of the chromium concentration.

\section{Extrapolation}

The work done here was primarily designed to make estimates of temperatures and irradiation doses where no experiments can be carried out for more than a decade whilst appropriate reactors 

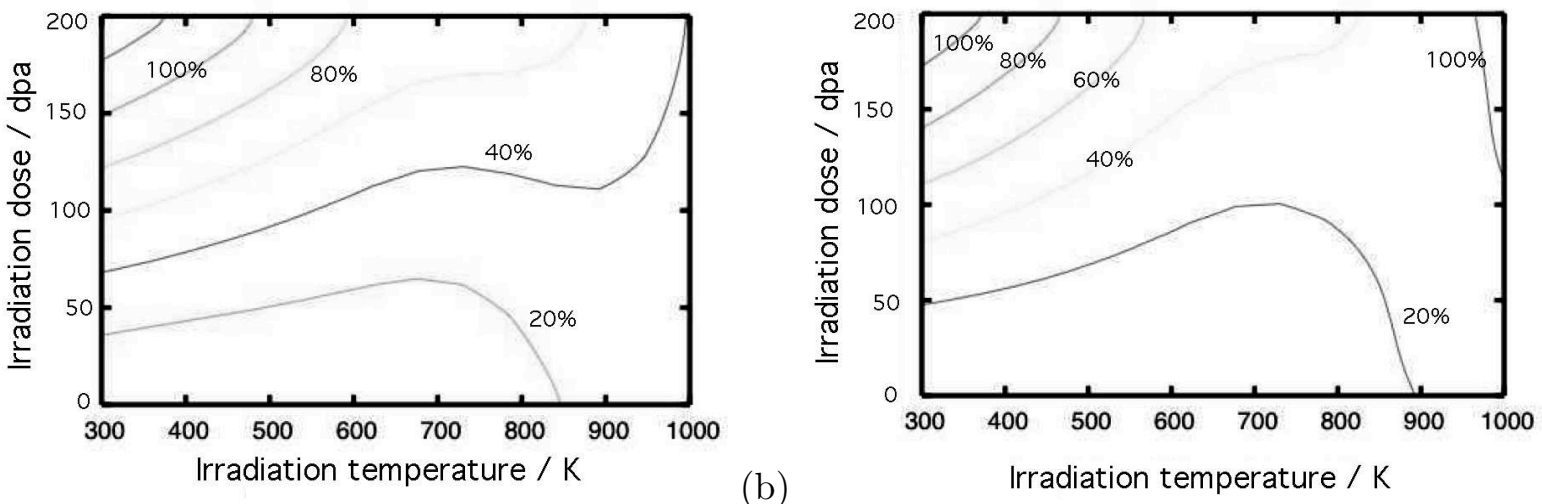

(a)

(b)

Figure 8: (a) Predicted \% elongation for Eurofer'97. (b) Corresponding uncertainties.

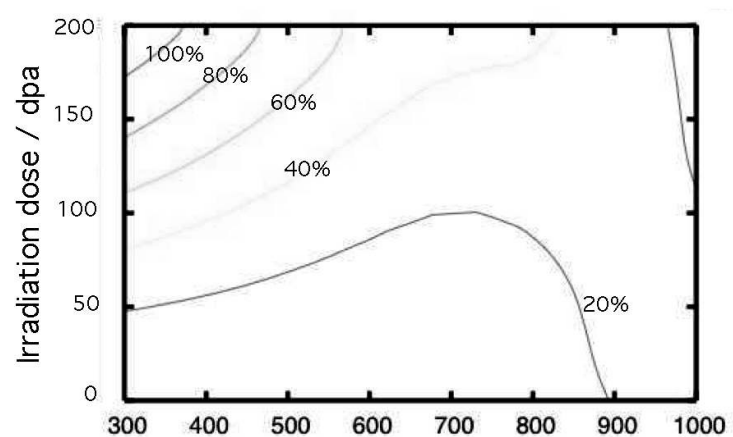

(a)

Irradiation temperature / K

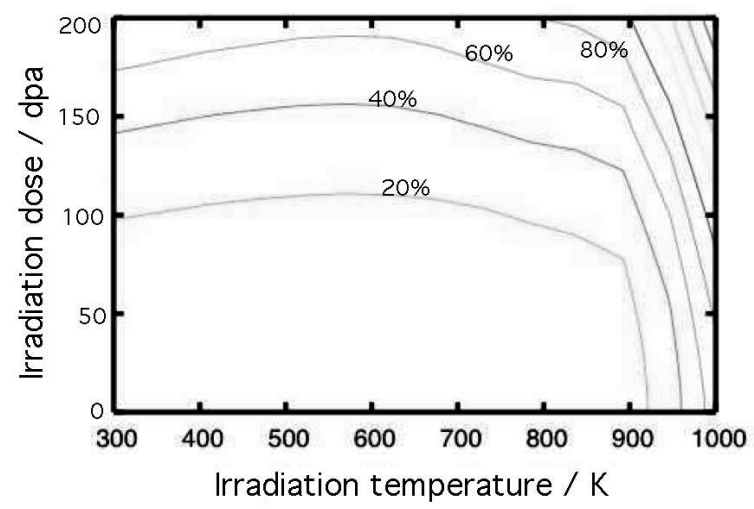

Figure 9: (a) Predicted \% elongation for Eurofer'97. (b) Corresponding uncertainties.

are built, i.e. for high temperatures (900 K) and irradiation doses (200 dpa). The ability of the network to extrapolate and to indicate uncertainties is therefore important.

Elongation was calculated between 300 and $1000 \mathrm{~K}$ and 0 and $200 \mathrm{dpa}$ for two low-activation steels: Eurofer'97 [30] and F82H [31]. The chemical compositions are given in Table 6; both steels had the same heat treatment: $1 \mathrm{~h}$ at $1323 \mathrm{~K}$ and $1 \mathrm{~h}$ at $1023 \mathrm{~K}$. Figures 8 and 9 show the results.

Table 4: Chemical composition in wt\%. The $\mathrm{Nb}$ and Mo concentrations are zero.

\begin{tabular}{lcccccccccccc}
\hline Alloy & $\mathrm{C}$ & $\mathrm{Cr}$ & $\mathrm{W}$ & $\mathrm{Ta}$ & $\mathrm{V}$ & $\mathrm{Si}$ & $\mathrm{Mn}$ & $\mathrm{N}$ & $\mathrm{Cu}$ & $\mathrm{Ni}$ & $\mathrm{P}$ & $\mathrm{Ti}$ \\
\hline Eurofer & 0.12 & 8.99 & 1.1 & 0.14 & 0.19 & 0.07 & 0.44 & 0.017 & 0.022 & 0.007 & 0 & 0.009 \\
F82H & 0.093 & 7.65 & 1.98 & 0.038 & 0.18 & 0.09 & 0.49 & 0.002 & 0 & 0.05 & 0.001 & 0 \\
\hline
\end{tabular}

The elongation reaches 140 and $120 \%$ for Eurofer' 97 and F82H at room temperature and 200 dpa. It reaches 80 and $60 \%$ in fusion conditions (900 K, $200 \mathrm{dpa}$ ) but the associated uncertainties are large (Figs. 8, 9). 


\section{Discussion and Conclusions}

There have been previous attempts in the context of fusion materials, to model and extrapolate irradiation behaviour using a neural network $[5,6]$. There are two fundamental differences with the work presented here. The previous effort did no include any heat treatment within the input parameters and this is definitely known to be important in determining the physical properties of creep-resistant steels.

Secondly, in order to avoid negative predictions, previous work emulated [32] in using a logarithmic function of the output. Although theoretically justified for transformation kinetics [32], it has been pointed out this procedure may when applied without justification lead to a biasing of the model $[33,34]$. The model was not trained on an output $y$ directly but on $Y$ :

$$
Y=\ln \left(-\ln \left(\frac{y-y_{\min }}{y_{\max }-y_{\min }}\right)\right)
$$

where $y_{\max }$ and $y_{\min }$ are the maximum and minimum values in the database. This equation is equivalent to

$$
-\exp (Y)=\ln \left(\frac{y-y_{\min }}{y_{\max }-y_{\min }}\right)
$$

$-\exp (Y)$ being strictly negative implies that $\left(\frac{y-y_{\min }}{y_{\max }-y_{\min }}\right)$ is smaller than 1 and $y$ is thus bounded by $y_{\min }$ and $y_{\max }$. Training the model on a logarithmic values induces an upper and a lower limit for the predicted values and hence biases the model. This is particularly the case when extrapolating over long ranges.

The main suggestions to reduce modelling uncertainties and increase the reliability of the model in areas far from the domain of available knowledge must come from a better understanding of hardening mechanisms or the realisation of more irradiation experiments at high doses/temperatures. Better irradiation experiment reports which include parameters often neglected (such as irradiation time, flux, complete chemical composition, etc) could also contribute to refining predictions. Finally, models should in normal circumstances be directly trained on the output itself rather than a bounding function of the output.

One important conclusion from this work is that elongation per se is not necessarily optimised at a concentration of $9 \mathrm{wt} \%$ of chromium; other factors intervene to give that impression.

This model is freely available online on the Materials Algorithms Project: http://www.msm.cam.ac.uk/map/mapmain.html

\section{Acknowledgement}

We are grateful to the Engineering and Physical Sciences Research Council for supporting this work. 


\section{References}

[1] E. A. Little, D. J. Mazey, and W. Hanks. Effects of ion irradiation on the microstructure of an ODS steel. Scripta Metallurgica and Materialia, 25:1115-1118, 1991.

[2] F. Abe, H. Araki, and T. Noda. Microstructural evolution in bainite martensite and deltaferrite of low activation Cr-2W ferritic steels. Materials Science and Technology, 6:714-723, 1990.

[3] R. L. Klueh, D. J. Alexander, and E. A. Kenik. Development of low-Cr, Cr-W steels for fusion. Journal of Nuclear Materials, 227:11-23, 1995.

[4] Dale L. Smith, Richard F. Mattas, and Michael C. Billone. Fusion reactor materials. In Brian R.T. Frost, editor, Materials Science $\&$ Technology, chapter 10, pages 245-340. WileyVCH, 1997.

[5] R. Kemp, G. A. Cottrell, H. K. D. H. Bhadeshia, G. R. Odette, T. Yamamoto, and H. Kishimoto. Neural-network analysis of irradiation hardening in low-activation steels. Journal of Nuclear Materials, 348:311-328, 2006.

[6] G. A. Cottrell, R. Kemp, H. K. D. H. Bhadeshia, G. R. Odette, and T. Yamamoto. Neural network analysis of Charpy transition temperature of irradiated low-activation martensitic steels. Journal of Nuclear Materials, 367-370:603-609, 2007.

[7] Y. Kojchi, I. Hiroshi, T. Hideo, Y. Masayoshi, K. Osamu, K. Kiyoshi, and K. Kazuhio. NRIM data sheets 1b, 3b, 8b, 11b, 12b, 17b, 18b, 19b, 20b, 21b. Technical report, National Research Institute for Metals, Tokyo, Japan, 1994.

[8] P. Jung, C. Liu, and J. Chen. Retention of implanted hydrogen and helium in martensitic stainless steels and their effects on mechanical properties. Journal of Nuclear Materials, 296:165$173,2001$.

[9] D. J. C. MacKay. Practical bayesian framework of backpropagation networks. Neural Computation, 4:448-472, 1992.

[10] D. J. C. MacKay. Bayesian interpolation. Neural Computation, 4:415-447, 1992.

[11] H. K. D. H. Bhadeshia. Neural networks in materials science. ISIJ International, 39:966-979, 1999.

[12] D. J. C. MacKay. Information Theory, Inference, and Learning Algorithms. Cambridge University Press, 2003.

[13] H. K. D. H. Bhadeshia, D. J. C. MacKay, and L.-E. Svensson. The impact toughness of CMn steel arc-welds - a Bayesian neural network analysis. Materials Science and Technology, 11:1046-1051, 1995.

[14] T. Cool, H. K. D. H. Bhadeshia, and D. J. C. MacKay. The yield and ultimate tensile strength of steel weld metals. Materials Science and Engineering A, 223A:186-200, 1997.

[15] S. B. Singh and H. K. D. H. Bhadeshia. Estimation of bainite plate-thickness in low-alloy steels. Materials Science and Engineering A, A245:72-79, 1998. 
[16] E. A. Metzbower, J. J. DeLoach, S. H. Lalam, and H. K. D. H. Bhadeshia. Neural network analysis of strength and ductility of welding alloys for high strength low alloy shipbuilding steels. Science and Technology of Welding, 6:116-121, 2001.

[17] T. Sourmail and C. Garcia-Mateo. A model for predicting the martensite-start temperature of steels. Computational Materials Science, 34:213-218, 2005.

[18] C. Garcia-Mateo, T. Sourmail, F. G. Caballero, and C. Garcia de Andrés. New approach for the bainite start temperature calculation in steels. Materials Science and Technology, 21:934-940, 2005.

[19] C. Capdevilla, C. Garcia-Mateo, F. G. Caballero, and C. Garcia de Andres. Neural network analysis of the influence of processing on strength and ductility of automotive low carbon sheet steels. Journal of Materials Science, 38:192-201, 2006.

[20] S. Chatterjee. TRIP-assisted steels. PhD thesis, University of Cambridge, 2006.

[21] S. Chatterjee, H. S. Wang, J. R. Yang, and H. K. D. H. Bhadeshia. Mechanical stabilisation of austenite. Materials Science and Technology, 22:641-644, 2006.

[22] S. Chatterjee and H. K. D. H. Bhadeshia. Stretch-flangeability of strong multiphase steels. Materials Science and Technology, 23:606-609, 2007.

[23] G. A. Cottrell, R. Kemp, and H. K. D. H. Bhadeshia. Designing optimised experiments for the international fusion materials irradiation facility. Journal of Nuclear Materials, 367-370:1586$1589,2007$.

[24] H. K. D. H. Bhadeshia. Design of ferritic creep-resistant steels. ISIJ International, 41:621-640, 2001.

[25] T. Morimura, A. Kimura, and H. Matsui. Void swelling of japanese candidate martensitic steels under FFTF/MOTA irradiation. Journal of Nuclear Materials, 239:118-125, 1996.

[26] R. L. Klueh and J. M. Vitek. Fluence and helium effects on the tensile properties of ferritic steels at low temperatures. Journal of Nuclear Materials, 161:13-23, 1989.

[27] R. L. Klueh and J. M. Vitek. Ferritic Alloys for Use in Nuclear Energy Technologies, page 615. The Metallurgical Society of AIME, Warrendale, Pennsylvania, 1984.

[28] R. L. Klueh. Heat treatment. Metallurgical and Materials Transactions A, 20(3):463-470, 1989.

[29] A. Kohyama, A. Hishinuma, D. S. Gelles, R. L. Klueh, W. Dietz, and K. Ehrlich. Lowactivation ferritic and martensitic steels for fusion application. Journal of Nuclear Materials, 233-237:138-147, 1996.

[30] E. Lucon and R. Chaouadi. Characterisation of the mechanical properties of EUROFER in the unirradiated and irradiated condition. Scientific Report SCK-CEN-BLG-945, Belgian Nuclear Research Centre, 2003.

[31] A. F. Rowcliffe, J. P. Robertson, R. L. Klueh, K. Shiba, D. J. Alexander, M. L. Grossbeck, and S. Jitsukawa. Fracture toughness and tensile behavior of ferritic-martensitic steels irradiated at low temperatures. Journal of Nuclear Materials, 258-263:1275-1279, 1998. 
[32] M. Yescas, H. K. D. H. Bhadeshiaj, and D. J. C. MacKay. Retained austenite in austempered ductile cast irons. Materials Science $\& 3$ Engineering A, 311:162-173, 2001.

[33] J. H. Pak. Charpy properties of welds. Master's thesis, Pohang University of Science and Technology, Pohang, Korea, 2007.

[34] J. H. Ryu. The mechanical properties of hot-rolled steels. Master's thesis, Pohang University of Science and Technology, Pohang, Korea, 2007. 